\title{
Phytochemical and Antioxidant Activities of Selected Ornamental Plants in the Philippines
}

\author{
Ruth T. Libag ${ }^{1,2}$ \\ ${ }^{1}$ College of Arts \& Sciences, Pampanga State Agricultural University, PAC Magalang, \\ Pampanga, Philippines, Phone No. +6345 866 0800, libag.ruth@psau.edu.ph \\ ${ }^{2}$ Graduate School, Angeles University Foundation, Angeles City 2009, Philippines
}

\begin{abstract}
The Philippines being considered as an important biodiversity hotspot in the world, possess a rich source of flora. Some ornamental plants are found to be sources of drugs being used to treat various ailments. This study aimed to focus on screening phytochemicals natural antioxidants present in locally available ornamental plants in the Philippines. The samples used in the study were the crude ethanolic leaf extracts of White angel (Wrightia antidysenterica L. R.Br.), Cabbage rose (Rosa sp.), Calachuchi (Plumiera alba) and,Ilang ilang (Cananga odorata). Phytochemicals from the samples were qualitatively identified using different spray reagents by Thin Layer Chromatography (TLC), while Free Radical Scavenging Activities of the samples were determined using DPPH Assay and Ascorbic acid as standard.

Results showed that the plant samples are positive for the presence of anthraquinones, coumarins, phenols, steroids/sterols. All have triterpenes except, Cananga odorata. Furthermore, bothWrightia antidysenterica L. R.Br.and Plumiera Alba have alkaloids, while flavonoids, sugars, and tannins are present in Wrightia antidysenterica $L$. $R$.Br.andCananga odorata. All have antioxidant activities (expressed as $\mathrm{EC}_{50}$ ) against the free radical DPPH at varying amounts. Antioxidant activity of the plant samples were found in following order: Ascorbic acid $(38 \mu \mathrm{g} / \mathrm{ml})>$ Rosa $s p .(76 \mu \mathrm{g} / \mathrm{mL}) \quad>$ Wrightia antidysenterica L. R.Br. $(107 \mu \mathrm{g} / \mathrm{mL})>$ Cananga odorata $(139 \mu \mathrm{g} / \mathrm{mL})>$ Plumiera alba $(203$ $\mu \mathrm{g} / \mathrm{mL})$. This study highlighted that indigenous ornamental plants in the Philippines are promising alternative sources of compounds with medicinal values.
\end{abstract}

Keywords: Ornamental plants, Wrightia antidysenterica L. R.Br., Rosa sp., Plumiera alba, Cananga odorata, Phytochemistry, Antioxidant, DPPH

Corresponding Author:Ruth T. Libag, libag.ruth@psau.edu.ph

\section{INTRODUCTION}

Plants remain to be the most valuable sources of biologically active natural products. They are reservoirs of important compounds with medicinal properties, as well as sources of therapeutic agents for the maintenance of health for over 5,000 years. Many kinds of research on natural molecules and products are focused on plants due to the fact that they can easily be sourced and selected based on their ethno-medicinal use [1].Recently, there is an increase in interest in the use of plant natural products for medicinal use. The World Health Organization (WHO) reported that one-third of the world's population has no access to medical care, relying primarily on the use of traditional remedies [2]. It was also reported that $70-95 \%$ of the world's total population still depends on traditional medicines for their primary health care needs [3, 4].They are important sources of diverse bioactive and 
therapeutic compounds. Natural products represent about fifty percent of all clinically used drugs [5]. This trend led to the discovery of different active compounds that are derived from plants. In the last decades, more and more new materials derived from plants have been authorized and subscribed as medicines [4].The uses of these bioactive plant-derived compounds are increasing because they are proven to be safe and are relatively less expensive as compared to commercially-produced medicines [6].

However, WHO also reported that as the use of traditional or alternative medicines increases, so do reports of adverse reactions that lead to various public health issues concerning their safety. Although some herbal medicines have promising potential and are widely used, many of them remain untested and their use also not monitored. This makes knowledge of their potential adverse effects very limited and identification of the safest and most effective therapiesmore difficult. WHO addresses the issue on appropriate access, safe and effective use of alternative medicines by releasing guidelines for health authorities to develop reliable information on alternative medicine use $[7,8]$.

To date, a number of prescription medicines contain different plant products. They have medicinal values that depend on some chemical substances or group of compounds to produce a definite physiological action to the body [9]. An effective approach for the discovery of new therapeutic agents is by screening the phytochemicals present [10].

Phytochemicals like plant alkaloids possess potent pharmacological effects that include analgesic, muscle relaxant, antimicrobial, potent anti-cancer, as well asanti-agingandantiviral properties $[11,12]$. Anthraquinones have been found as laxatives, diuretics, phytoestrogens, immune stimulators, antifungal agents, antiviral agents, and anticancer agents[13]. Triterpenes act as anti-inflammatory, antiviral, antimicrobial, antitumoral agents, and immunomodulator compounds [14]. Plant steroids have anti-tumor, immunosuppressive, hepatoprotective, antibacterial, plant growth hormone regulator, sex hormone, antihelminthic, cytotoxic and cardiotonic activity [15]. Flavonoids and other polyphenols have drawn increasing attention due to their potential beneficial effects on human health as antioxidants [16]. Theyscavenge free radicals such as peroxide, hydroperoxide or lipid peroxyl and thus inhibit the oxidative mechanisms that lead to degenerative diseases[17].Oxidative stress results from an imbalance of oxidizing species and natural antioxidants in the body have been thought to have contributed to aging, cell apoptosis, and severe diseases such as cancer, Parkinson's disease, Alzheimer's disease, and even cardiovascular disorders. Epidemiological studies and intervention trials on the prevention of cancer and cardiovascular disease are suggestive that dietary intake of antioxidants can help free radicals and oxidants and protect the body against diseases [18].In addition, there has been growing interest in natural antioxidant because they have greater application in the food industry for increasing the stability and shelf-life of food products [19]. There are studies on the medicinal uses of some ornamental plants, but there is still aneed to establish scientifically and later on isolate and characterize the bioactive components from these sources.

Several ornamental plant species are traditionally being used for the treatment of common ailments. An example of these ornamental plants is Catharanthus roseus or Rosy periwinkle which is a known source of an anti-cancer agent, vinblastine [20, 21]. Further studies showed that it also has a number of activities like antidiabetic, bactericide, antioxidant and antihypertensive properties [22]. To name a few other flowering plants, an Amaryllidaceae alkaloid, Galantamine (Reminyl ${ }^{\circledR}$ ), from Galanthus woronowii is being used for Alzheimer treatment due to its activity as a selective acetylcholinesterase inhibitor [23, 24]. Moreover, 
another flowering plant is the source of Apomorphine hydrochloride (Apokyn ${ }^{\circledR}$ ) a dopamine receptor agonist produced in Papaver somniferumL. andis used to treat Parkinson's disease [25].

The Philippines, being one of the most important biodiversity hotspots in the world, houses an eclectic variety of flora [26]. These plants contribute to the nation's increasing collections of natural resources which are also potential medicinal plants if properly screened and analyzed. Most of the species in the flowering plants Apocynaceae are used in traditional medicine. One of the plants under this family that is traditionally used in India as anticancer and antihypertensive is the White Angel (Wrightia antidysenterica L. R.Br.) [27]. The plant is now seen almost everywhere in the Philippines because it thrives to various types of soil. The essential oils of Rosaceae, on the other hand, exhibited antifungal and antibacterial properties [28]. Plumeria alba (Calachuchi) is mainly grown in the Philippines as an ornamental plant, with the flowers as its main attraction. Calachuchi has a variety of medicinal properties such as purgative and used as a remedy for itching. Lastly, Cananga odorataor Ilang ilang means "flowers of flowers." The oil extracted from fresh flowers has a floral fragrance. Its properties are sedative, antidepressant, and nervous system tonic [29].

In view of these properties of ornamental plants, a continuous and systematic effort in finding new compounds from natural sources must be undertaken to scientifically establish their medicinal values. It was in this endeavor that the researcher analyzed the crude ethanolic extracts of the different parts of locally available ornamental plants in the Philippines namely; White angel (Wrightia antidysenterica L. R.Br.), Cabbage rose (Rosa sp.), Calachuchi (Plumiera alba) and,Ilang ilang (Cananga odorata).

Specifically, this study sought to qualitatively identify the presence of phytochemicals using different spray reagents by Thin Layer Chromatography (TLC), as well as, evaluate the Free Radical Scavenging Activities of the test samples using DPPH Assay and Ascorbic acid as standard.

\section{MATERIALS AND METHODS}

Collection and Identification of Plant Samples. The leaves of White angel (Wrightia antidysenterica L. R.Br.), Cabbage rose (Rosa sp.), Calachuchi (Plumiera alba) and,Ilang ilang (Cananga odorata) were brought to the National Museum and were properly identified and were given authentication by professional botanists. Plants were collected according to the procedures specified in the Plant Screening Guidebook by Guevarra et.al. [30]. Plant specimens were washed and air dried at room temperature for two weeks.

Extraction and Concentration of Plant Samples. The dried materials were cut into smaller pieces and ground into powder. By the use of solvent extraction method, diluted $80 \%$ ethyl alcohol was used to completely submerge the material. The filtered extracts were collected after 48 hours of soaking in ethanol and concentrated under pressure at a temperature not exceeding $40^{\circ}$ Celcius using rotary evaporator.

Phytochemical screening [30]. The standard protocol of Guevarra et.al was used in the Qualitative phytochemical screening by Thin-Layer Chromatography (TLC) using Silica gel $60 \mathrm{~F}_{254}$ to analyze the constituents of the plant samples. The spots were visualized using Ultraviolet (UV) lamp and by using different spray reagents. The spray reagents used are the following: Antimony (III) chloride, Potassium-ferricyanide-ferric chloride, Acetic anhydridesulfuric acid, Dragendorff's reagent (Munier Machebouef), 3-5 Dinitrobenzoic acid (Kedde reagent), Methanolic potassium hydroxide (Bornträger reagent), and Magnesium acetate in methanol. Each of the reagents used indicates the presence of specific phytochemical like 
alkaloids, anthraquinones, anthrones, coumarins, flavonoids, phenols, steroids, sugars, tannins, and triterpenes.

Antioxidant Assay: DPPH Free Radical Scavenging Activity. The stable DPPH radical model is a widely used, relatively quick and precise method for the evaluation of free radical scavenging activity. The DPPH radical accepts an electron or hydrogen radical to become a stable diamagnetic molecule. On the interaction of antioxidant with DPPH allows transfer electron or hydrogen atom to DPPH and thus neutralizing its free radical character and convert it to 1-1,diphenyl-2- picryl hydrazine. The degree of purple discoloration indicates the scavenging activity of the drug. The reduction capacity of antioxidants in the crude against DPPH radical is determined by the decrease in its absorbance at $520 \mathrm{~nm}$. The decrease in absorbance of DPPH radical caused by the antioxidants present in the samples is equivalent totheir scavenging capacity on the radical by hydrogen donation. It is visually noticeable as a change in color from purple to yellow [31, 32].

The DPPH Assay was patterned on the procedure used by Molyneux [33]. The DPPH reagent was prepared by dissolving $0.0100 \mathrm{~g}$ of $\mathrm{DPPH}$ in $80 \%$ ethanol to make a concentration of $100 \mu \mathrm{M}$ solution. A calibration curve was constructed using ascorbic acid as standard. All the samples and standards were tested in triplicates.

Antioxidant activity, in terms Free radical scavenging Activity,or the ability to eradicate 50\% of DPPH expressed in terms of Efficient concentration $50\left(\mathrm{EC}_{50}, \mathrm{Q}\right)$ for each of the samples was computed using the following formula.

$$
\mathrm{Q}=100 \frac{(\mathrm{Ao}-\mathrm{Ac})}{\mathrm{Ao}}
$$

Where: Ao $=$ the absorbance of positive control containing DPPH only

$\mathrm{Ac}=$ absorbance of the solution containing extracts and DPPH.

\section{RESULTS AND DISCUSSION}

Table 1 shows a profile of the different Phytochemicals found in the different ornamental plants used in this study.

Table1. Phytochemical Properties of Selected Ornamental Plants

\begin{tabular}{|c|c|c|c|c|}
\hline PHYTOCHEMICALS & $\begin{array}{c}\text { White angel } \\
\text { (Wrightia } \\
\text { antidysenterica } \\
\text { L. R.Br. })\end{array}$ & $\begin{array}{c}\text { Rose } \\
(\text { Rosa sp. })\end{array}$ & $\begin{array}{c}\text { Calachuchi } \\
\text { (Plumiera } \\
\text { Alba })\end{array}$ & $\begin{array}{c}\text { Ilang ilang } \\
\text { (Cananga } \\
\text { odorata })\end{array}$ \\
\hline Alkaloids & + & - & + & - \\
\hline Anthraquinones & + & + & + & + \\
\hline Coumarins & + & + & + & + \\
\hline Flavonoids & + & - & - & + \\
\hline Phenols & + & + & + & + \\
\hline Steroids/sterols & + & + & + & + \\
\hline Sugars & + & - & - & + \\
\hline Tannins & + & - & - & + \\
\hline Triterpenes & + & + & + & - \\
\hline
\end{tabular}


Results showed that all the plant samples are positive for the presence of anthraquinones, coumarins, phenols, steroids/sterols. These indicate their broad potential as antiviral, antifungal, anti-inflammatory, antibacterial, antioxidant and anticancer properties to name a few $[13,15,16]$. All the plant samples have triterpenes except, Cananga odorata which imply their potential as anti-inflammatory, antiviral, antimicrobial, antitumoral and immunomodulatory activities [14]. Furthermore, bothWrightia antidysenterica L. R.Br.and Plumiera Alba have alkaloids that make these compounds as potential sources of analgesic, antimicrobial, anti-cancer, anti-aging and antiviral agents [11,12], while flavonoids, sugars, and tannins present in Wrightia antidysenterica L. R.Br. andCananga odoratacontribute to theirantioxidant properties [16,17].

On the other hand, Table 2 shows the antioxidant activity in terms of $\mathrm{EC}_{50}$ values of the different plant samples and vitamin $\mathrm{C}$ against $100 \mu \mathrm{M}$ DPPH.

Table 2. DPPH Free Radical Scavenging Activity

\begin{tabular}{|c|c|}
\hline Plant Sample & EC $_{\mathbf{5 0}}$ value (ug/mL) \\
\hline Wrightia antidysenterica $L$. R.Br. & $107 \mu \mathrm{g} / \mathrm{mL}$ \\
\hline Rosa sp. & $76 \mu \mathrm{g} / \mathrm{mL}$ \\
\hline Plumiera alba & $203 \mu \mathrm{g} / \mathrm{mL}$ \\
\hline Cananga odorata & $139 \mu \mathrm{g} / \mathrm{mL}$ \\
\hline Ascorbic acid & $38 \mathrm{ug} / \mathrm{mL}$ \\
\hline
\end{tabular}

Table 2 shows the DPPH radical scavenging activities of standard ascorbic acid and ornamental plants. The extract of Rosa sp. showed the highest DPPH scavenging activity and compared with ascorbic acid as standard $\mathrm{EC}_{50}$ value is $38 \mu \mathrm{g} / \mathrm{mL}$ while the $\mathrm{EC}_{50}$ value is 38 $\mu \mathrm{g} / \mathrm{mL}$. Antioxidant activity of the leaf ethanolic extracts of ornamental plants were showed in following order: Ascorbic acid $(38 \mu \mathrm{g} / \mathrm{ml})>$ Rosa sp. $(76 \mu \mathrm{g} / \mathrm{mL})>$ Wrightia antidysenterica L. R.Br. $(107 \mu \mathrm{g} / \mathrm{mL})>$ Cananga odorata $(139 \mu \mathrm{g} / \mathrm{mL})>$ Plumiera alba $(203 \mu \mathrm{g} / \mathrm{mL})$.

Figure 1 shows the Free Radical Scavenging Activities (FRSA) of the plant samples. The amount of DPPH inhibited by $125 \mu \mathrm{g} / \mathrm{mL}$ of plant samples is expressed as percentage.

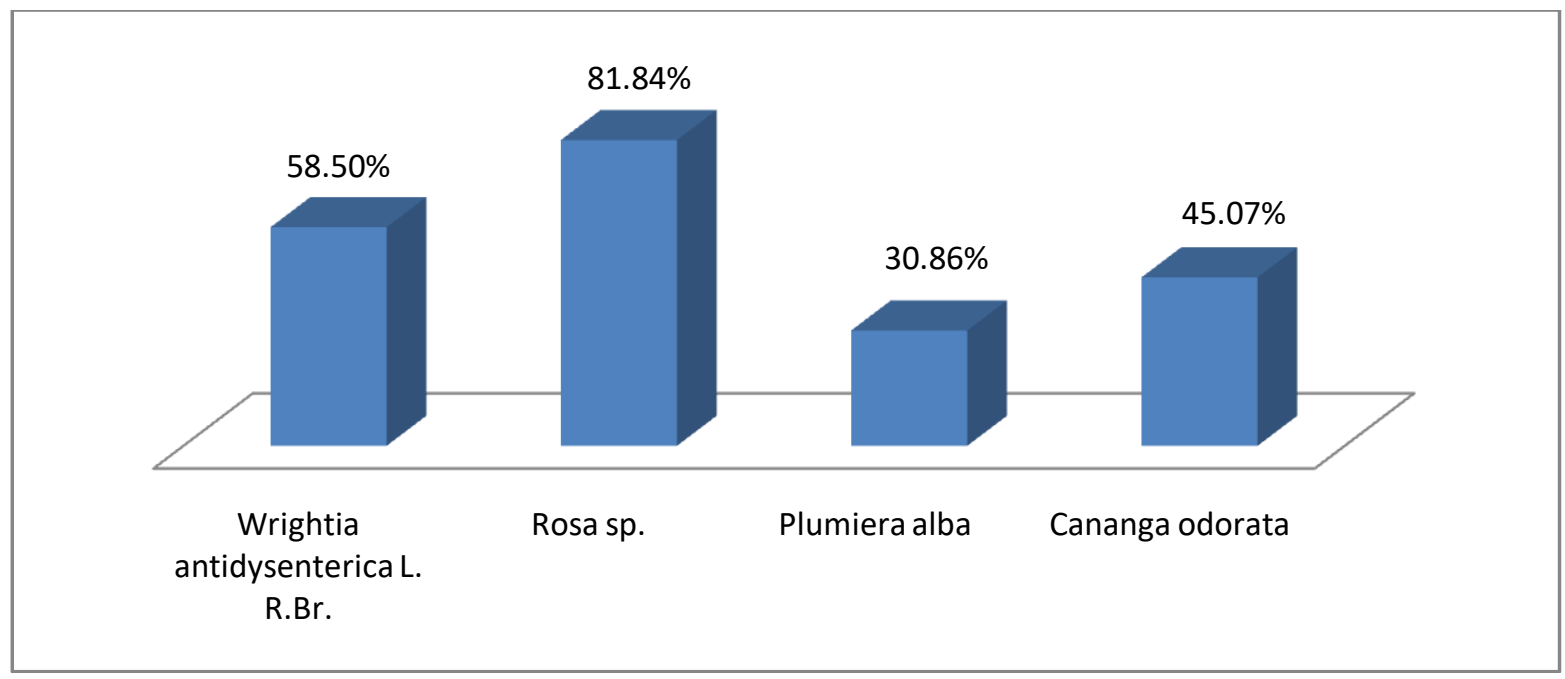

Fig. 1 Free Radical Scavenging Activities of the crude ethanolic leaf extracts

Among the four plant samples, Rosa sp. had the highest Free Radical Scavenging Activity that was able to inhibit $81.84 \%$ of DPPH radical. This is followed by Wrightia antidysenterica L. R.Br (58.50\%)., Cananga odorata(45.07\%), andPlumiera alba(30.86\%), respectively. 


\section{CONCLUSION}

Inconclusion, the results of the present study showed that the ornamental plants namely; White angel (Wrightia antidysenterica L. R.Br.), Cabbage rose (Rosa sp.), Calachuchi (Plumiera alba) and,Ilang ilang (Cananga odorata)contain various phytochemicals that make them potential sources of compounds with medicinal values.

All the plant samples have antioxidant activity against the free radical DPPHat varying degrees. Cabbage rose (Rosa sp.) has the highest antioxidant activity followed by White angel (Wrightia antidysenterica L. R.Br.), Ilang ilang (Cananga odorata), and Calachuchi (Plumiera alba). The results showed that the ornamental plants in this study possess phytochemicals and antioxidants that make them promising alternative medicinal sources.

\section{REFERENCES}

[1] R. Verpoorte, YH Choi, HK Kim. Ethanopharmacology and system biology: a perfect holistic match. J Ethnopharmacol, vol. 100, pp. 53-56, 2005.

[2] G. Bodeker, CK Ong, C. Grundy, G. Burford, K. Shein, et al. WHO global atlas of traditional, complementary and alternative medicine, 2005.https://apps.who.int/iris/handle/10665/43108

[3] M.Ekor The growing use of herbal medicines: issues relating to adverse reactions and challenges in monitoring safety. Front Pharmacol., vol. 4, pp. 177, 2014.doi:10.3389/fphar.2013.00177

[4] M. Fridlender, Y.Kapulnik, and H. Koltai. Plant derived substances with anti-cancer activity: from folklore to practice. Front. Plant Sci., 2015. https://doi.org/10.3389/fpls.2015.00799

[5] I. Ahmad, F. Aqil, and M. Owais. Modern Phytomedicine, Turning Medicinal Plants into Drugs.WILEY-UCH Verlag GmbH Co. KGa, 2006.

[6] E. Kateregga, T. Sterner. Indicators for an invasive species: water hyacinths. Ecol.Ind, vol. 7(2), pp 362-370, 2007.

[7] WHO, 2004. https://www.who.int/mediacentre/news/releases/2004/pr44/en/

[8] WHO 2002. Traditional Medicine Strategy (2002-2005). WHO/EDM/TRM/2002.1. Geneva, Switzerland: World Health Organization

[9] N. Peteros, \&M. Uy. Antioxidant and cytotoxic activities and phytochemical screening of four Philippine medicinal plants. Journal of Medicinal Plants Research, vol. 4(5), pp. 407-414, 2010.

[10] N. Savithramma, S. Ankanna, ML Rao, J. Saradvathi. Studies on antimicrobial efficacy of medicinal tuberous shrub Talinum cuneifolium. J Environ Biol, vol. 33, pp. 775-780, 2012.

[11] S. O'Connor. Alkaloids in comprehensive natural products II L. Mander, H-W. Lui, Eds. Elsevier, Oxford, vol. 1, pp. 977-1007. 5, 2010.

[12]N. Bribi. Pharmacological activity of Alkaloids: A Review. Asian Journal of Botany, vol. 1, pp. 1-6, 2018. doi:10.63019/ajb.v1i2.467

[13] S. Siddiquee. Recent Advancements on the Role and Analysis of Volatile Compounds (VOCs) from Trichoderma, Chapter 11, Pages 139-175, 2014.

[14] J.L Rois. Effects of triterpenes on the immune system. Journal of Ethnopharmacology, vol. 128(1), pp. 1-14, 2010. DOI:10.1016/j.jep.2009.12.045

[15] Systematic review of plant steroids as potential anti-inflammatory agents: Current status and future perspectives. The Journal of Phytopharmacology, vol. 4(2), pp. 121-125, 2015 . 
[16] M.G. Repetto and S.F. Llesuy. Antioxidant Properties of natural compounds used in popular medicine for gastric ulcers. Brazilian Journal of Medical and Biological Research, vol. 35,pp. 523-534, 2002. ISSN 0100-879X.

[17] A. Prakash. Antioxidant Activity. Medallion Laboratories: Analytical Progress, vol. 19 No. 2, 2001.

[18] B. Frei. Natural antioxidants in human health and disease. San Diego: Academic Press, 1994.

[19] K.P. Suja, A. Jayalekshmy \&C. Arumughan, C. Free radical scavenging behavior of antioxidant compounds of Sesame (Sesamum indicum L.) in DPPH System. Journal of Agricultural and Food Chemistry, vol. 52, pp. 912-915, 2004.

[20] L.P. Maema,M. Potgieter, and S.M. Mahlo.Invasive alien plant species used for the treatment of various diseases in Limpopo province, South Africa. African Journal of Traditional, Complementary and Alternative Medicine, vol. 13(4),pp. 223-231, 2016.

[21] J. Roepke, V. Salim, M. Wu, A.M. Thamm, J. Murata, K. Ploss, W. Boland, V. de Luca. Vinca drug components accumulate exclusively in leaf exudates of Madagascar periwinkle. Proc. Natl. Acad. Sci.USA, vol.107, pp. 15287-15292, 2010.

[22]L. Almagro, F. Fernández-Pérez and M.A. Pedreño. Indole Alkaloids from Catharanthus roseus: Bioproduction and Their Effect on Human Health. Molecules, vol. 20(2), pp. 2973-3000, 2015. doi:10.3390/molecules20022973.

[23] M. Heinrich and H.L. Teoh. Galanthamine from snowdrop-the development of a modern drug against Alzheimer's disease from local Caucasian knowledge. $J$. Ethnopharmaco, vol. 92, pp. 147-162, 2004. doi: 10.1016/j.jep.2004.02.012

[24]T. Pirttilä, G. Wilcock, L. Truyen, and C. Damaraju. Long-term efficacy and safety of galantamine in patients with mild-to-moderate Alzheimer's disease: multicenter trial. Eur. J. Neurol, vol. 11, pp. 734-741, 2004. doi: 10.1111/j.14681331.2004.00885.x

[25]D. Deleu,Y. Hanssens and M. Northway. Subcutaneous apomorphine. An evidencebased review of its use in Parkinson's disease. Drugs Aging, vol. 21, pp. 687-709, (2004). doi: 10.2165/00002512-200421110-00001

[26] G.Langenberger. A review on Philippine forest vegetation, particularly work since 1990. Agham Mindanao, vol. 2, pp. 11-24, 2004.

[27] P. Akhtar, M. Ali, M.P. Sharma, H. Farooqi, S. R. Mir and H. N. Khan. Development of Quality Standards of Holarrehena antidysenterica (Linn.) Bark. Recent Research in Science and Technology, vol. 31, pp. 73-80, 2011.

[28] J. S. Raut, S. M. Karuppayi. A status review on the medicinal properties of essential oils. Industrial Crops and Products, vol. 62, pp. 250-264, 2014.

[29]E. Quisumbing. Medicinal and Plants of the Philippines, Katha Publishing Company Inc., Philippines, 1978.

[30] B.Q. Guevarra (ed). A Guidebook to Plant Screening: Phytochemical and Biological. UST Manila, Philippines, 2005.

[31] M. Raghavendra, A. Madhusudhana reddy, Pulala Raghuveer Yadav, A. Sudharshan Raju, L. Siva Kumar. Comparative studies on the in vitro antioxidant properties of methanolic leafy extracts from six edible leafy vegetables of India. Asian Journal of Pharmaceutical and Clinical Research, vol. 6, issue 3, 2013.

[32] A. Braca, N. D. Tommasi, L.D. Bari, C. Pizza, M. Politi, I. Morelli. Antioxidant Principles from Bauhinia terapotensis. J Nat Prod, vol. 64, pp. 892-895, 2001.

[33]P. Molyneux. The use of the stable free radical diphenylpicrylhydrazyl (DPPH) for estimating antioxidant activity. Songklanakarin J. Sci. Technol., vol. 26(2), pp. 211219,2004 . 